\title{
Revista de Estudios
}

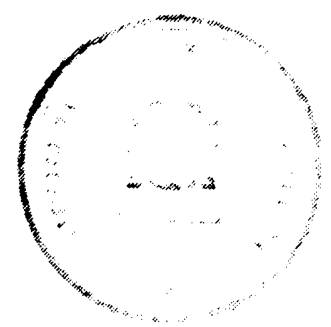

de laAdministración Local

"Autonómica

$$
237
$$

ENERO-MARZO 1988

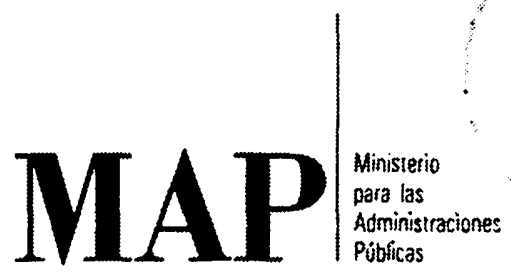

INAP Instituto Nacional de Administración Pública 
REALA-1988, núm. 237. PRIMERAS 
REALA-1988, núm. 237. PRIMERAS

REALA-1988, núm. 237. PRIMERAS 
REALA-1988, núm. 237. PRIMERAS

REALA-1988, núm. 237. PRIMERAS 


\section{Revista}

de Estudios

de la Administración

Local

${ }_{y}$ Autonómica

$$
237
$$

ENERO-MARZO 1988

INSTITUTO NACIONAL DE ADMINISTRACION PUBLICA 


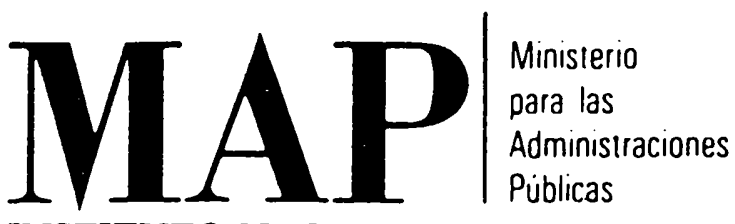

INSTITUTO NACIONAL DE ADMINISTRACION PUBLICA

Presidente del INAP:

Luciano Parejo Alfonso.

Director de la Revista:

Francisco Sosa Wagner.

Consejo Editorial:

Presidente: Ramón Martín Mateo.

Vocales: Lorenzo Martín Retortillo.

José L. Carro Martínez y Fernández Valmayor.

Pedro Escribano Collado.

Luis Ortega Alvarez.

Secretario de Redacción:

Carlos Menor Cassy.

Coordinación:

Subdirección General de Documentación y Publicaciones del INAP.

Redacción:

Santa Engracia, 7. 28010 Madrid.

Imprime: Boletín Oficial del Estado.

Depósito legal: M 1582/1958.

ISSN: 0213-4675.

NIPO: $329-88-008-0$.

Revista trimestral.

Precio de suscripción anual: 1.000 pesetas.

Número suelto: 300 pesetas. 